\section{Kennedy seeks legislation on women in science}

LEgislation establishing a ten-year programme to encourage the participation of women in scientific and technical careers has been introduced into the US Senate by Senator Edward M. Kennedy.

The proposed legislation would establish programmes, policies and procedures to enhance education for women in science and mathematics, to improve training and employment opportunities for women in science and technology, and to prevent discrimination against women in scientific and technical fields.

Particular emphasis would be placed on:

- A National Science Foundation programme aimed at interesting and involving female students in elementary and secondary school science and mathematics courses.

- A major effort by the NSF on increasing the participation of women in courses in both higher and continuing education.

- The setting up of a clearing house on women in science', provided with an annual authorisation of $\$ 3$ million, to collect, analyse and disseminate to the public information about employment in the public and private sectors.

- Various awards to be given to those who have contributed to the advancement of women in science.

Under the proposed legislation, the head of each federal agency, national laboratory and federally-funded research and development centre is to take action to prevent discrimination against women in science and technology, to increase opportunities for the employment and advancement of women in science and to encourage the participation of minority and physically handicapped women in science.

Introducing the bill, which would be known as the "Women in Science and Technology Equal Opportunity Act', Senator Kennedy said that the legislation was the result of a growing concern that there had been virtually no increase in the number of women in scientific careers over the past 50 years.

"Moreover those women who are working as scientists and engineers are earning less than men in every field, at every degree level, at every level of experience and in every employment setting. Further those women who are trained in scientific and technological fields are experiencing an unemployment rate from three to five times that of men in every field of science," Senator Kennedy said.

David Dickson
YEARS ago, Glasgow was considered to be a centre of rickets, resulting from deficient diets and paucity of sunlight. Alastair Hay (24 November, page 289) mentions Glasgow as again drawing attention to rickets, this time in a recrudescence of the disease in the children of Britain's Asian community. Fifty years ago, cod liver oil was the leading prescription for preventing rickets. Swallowing it was a grim reminder of a popular adage that things that tasted bad were good for you. This old remedy has long been displaced by cheaper and more abundant vitamin $\mathrm{D}$, which costs about $\$ 20$ for a million recommended daily allowances of 400 units (IU) (cod liver oil as a source of vitamin D costs 300 to 400 times as much). Why, indeed, should any child have rickets?

Most of the vitamins are promoted in overdoses to produce various forms of psychological comfort, a practice sometimes termed "acute remunerative therapy." Vitamin D is one of the two or three vitamins that are not in this category. It is not pushed in "megadoses" because its toxicity in amounts above 2,000 IU per day is well known. Except during pregnancy, there is no detectable need for additional vitamin $\mathrm{D}$ in most adults. These two circumstances evidently underlie the hesitation to add vitamin $\mathrm{D}$ to chapati fiour, as reported by Hay. Much of the milk retailed in the United States, including 'non-fat' milk, contains 400 IU of added vitamin D per quart. The adoption of this procedure was a milestone in public health nutrition, comparable to adding iodine to salt. The acceptance of such a step (immunisation is another example), depends upon benefit far outweighing risk, and upon the concept that people will participate in a measure that will help others, even though they themselves are not in need. I leave it to the sociobiologists to evaluate the matter in terms of re-

\section{Vitamin needs}

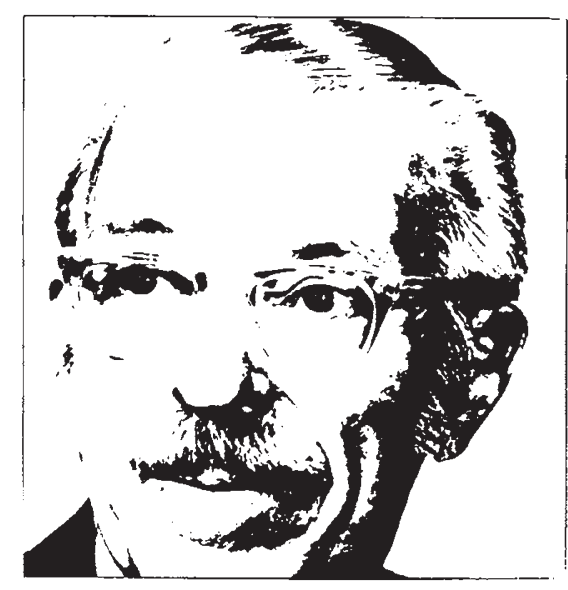

\section{THOMAS H. JUKES}

ciprocal altruism. Sometimes, however, there is a tendency for people to object to protection against a hazard with which they are no longer familiar, and which therefore is thought not to exist. This reminds one of doing away with firemen because no houses have burned down lately.
It is instructive to compare the nutritional treatment of domestic animals with that of human beings who eat them. Rickets was once a common disease in young chickens kept in poultry houses. It has long since vanished. Spurred by economics and competition, the drive to produce cheap vitamin $\mathrm{D}$ for poultry was a scientific success story. Chickens, and especially turkeys, could not effectively utilise the "plant" form of vitamin D, ergocalciferol, that sufficed for mammals. Ergocalciferol was made from ergosterol, present in yeast. Poultry needed the 'animal' form, cholecalciferol, that is derived from 7-dehydrocholesterol. At one time, Dupont dominated the market, which they entered in an interesting way.

First, they made a special plastic window for poultry houses that admitted ultraviolet light, which prevents rickets. Glass filters out the active wavelengths. Then they found an unusual source of 7-dehydrocholesterol in molluscs. But the organic chemists eventually outstripped the shellfish, so that vitamin D3, cholecalciferol, became plentiful. As often happens, human nutrition became the beneficiary of research in agriculture. For this to take place, people must learn to put knowledge to use.

You may be assured that, regardless of the plight of Asian children in Great Britain, the bone of the drumstick in your fried chicken at the fastfood outlet will contain a healthy $46 \%$ to $48 \%$ of ash, on a dry, fat-free basis. It is easier to get vitamins to chickens than to children. 